\title{
Self-perception of Stigma among Epilepsy Patients in Malaysia
}

\author{
${ }^{\mathrm{a} R M}$ Yousuf MD, ${ }^{\mathrm{a}}$ MA Shahar MMed, a OA Marzuki MMed, ${ }^{\mathrm{a}} \mathrm{SMS}$ Azarisman PhD, ${ }^{\mathrm{a} C}$ Rosle MMed, ${ }^{\mathrm{b}} \mathrm{MH}$ Tin Btw \\ ${ }^{a}$ Department of Internal Medicine, Faculty of Medicine, International Islamic University Malaysia \\ ${ }^{b}$ Medical statistics unit
}

\begin{abstract}
Introduction: Epilepsy remains a stigmatised disease across geographical and temporal boundaries. Very little is known about epileptic stigma (ES) in cross-cultural settings. The aim of this study was to assess the prevalence of perceived stigma and factors associated with it, among patients with epilepsy (PWE) at a tertiary care referral hospital in East Coast of Malaysia. Methods: A cross sectional survey among 132 consenting PWE using pre-tested, semi-structured questionnaire in Malay/English language to assess their knowledge, attitude and practices (KAPs). Results: Among 132 respondents, 51.5\% were male and $48.5 \%$ were female. Their age ranged from 14 to 70 years (mean=31.6 13.41$)$. Majority $(53.8 \%)$ of them were aged 30 years or younger. The median number of years they had epilepsy was 8.0 (IQR 4.0-18.8) years and average duration of seizure prior to seeking medical attention was 1.0 (IQR $0.3-4.5$ ) year. Most of them (90.9\%) did not know the cause of epilepsy; however nearly all (91.7\%) believed that it was a disease of the brain. Higher education level respondents possessed significantly higher KAP scores compared to lower education level respondents $(p<0.001)$. Respondents with good KAP scores believed that epilepsy was not contagious and they observed greater social tolerance. Conclusion: Our study suggests that there is an inverse relationship between knowledge and ES. Self-perceived stigma was more common among our PWE. The results suggest that there is a critical need to enhance epilepsy education amongst the PWE beyond mere seizure control.
\end{abstract}

KEYWORDS: Epilepsy, stigma, attitudes, prejudice, Malaysian population

\section{INTRODUCTION}

Epilepsy is the most common chronic neurological disorder characterized by recurring seizures. ${ }^{1}$ It can affect anyone at any age, in any race or social class, but is more prevalent in the early years of life. ${ }^{2}$ More than 50 million people worldwide suffer from it, $80 \%$ of whom live in economically backward and developing countries. ${ }^{3}$ Although around $70 \%$ of them respond to anti-epileptic treatment and are seizure-free, up to $25 \%$ suffer from refractory forms of epilepsy which prevents them from living

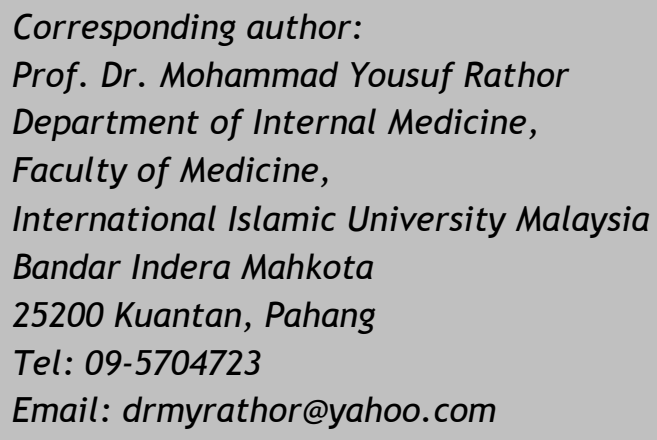

independent life. ${ }^{4-7}$ Despite scientific advances in different fields of epileptiology and its treatment, it is one of the most stigmatizing medical conditions as revealed by various recent studies from different parts of the world. ${ }^{8-16} \mathrm{~A}$ potential explanation for this universal impression is that seizures are dramatic and often scaring. The forced cry, the loss of consciousness, the fall, the twitching and the foaming at the mouth; all cause frightening among spectators.

The aetiology of stigma is complex, with multiple origins. The diagnosis of epilepsy brings about fears of being different accompanied by a negative selfevaluation, which impairs the patient's quality of life. It may arise as a direct consequence of experiencing others' fear or worry about having to deal with someone with epilepsy. Sufferers often try to conceal or deny their condition.

According to Goffman, people are stigmatised when they possess an element that is undesirable and "deeply discrediting" and the reaction of others spoils their normal identity. ${ }^{17}$ Another widely 
accepted definition of stigma is a social process or related personal experience characterised by rejection, blame accusation and societal devaluations. ${ }^{18}$ Based on these definitions ES has been divided in to three types.

a. Self-perceived stigma (or internalized stigma) refers to feeling of stigma of being epileptic which is often interpreted negatively, leading sometimes to an overwhelming feeling of shame. PWEs often internalise societal devaluations of them and as a consequence they assume that they will be stigmatised by others even without any such encounter, which causes them to adopt coping strategies through social isolation and withdrawal. ${ }^{19} \mathrm{It}$ may also become a self-fulfilling prophecy, in that fear and shame of being epileptic leads them to conceal it from others.

b. Enacted stigma refers to actual episodes of discrimination against PWEs, both formal and informal, only on the grounds that they suffer from epilepsy.

c. Courtesy stigma refers to ES that affects the whole family and even those who have an association with the patient. Thus having a child with seizures can lead to a feeling of guilt for many parents.

Epilepsy stigma (ES) is common global problem in all cultures, even though it variously presents in terms of both modality and content. It has deleterious effect on the patient's life more than the disease itself. Furthermore, the caregivers of PWE also undergo severe emotional, physical, and economic burden due to chronic disability, and stigma attached to it. ${ }^{20,21}$ It is the family members, particularly parents, whose negative reactions to a diagnosis of epilepsy in their child seem to set the stage for the child's stigma and he learns to think about epilepsy as something shameful. Enacted stigmas may be uncommon; whereas self-perceived stigma is much more prevalent. Further selfperceived stigma may cause more personal anguish and unhappiness than enacted stigma In a large cross cultural study of over 5,000 participants, $51 \%$ of PWEs felt stigma as a consequence of having epilepsy. ${ }^{22}$ The psychosocial impact of ES affects their self-esteem, the ability to gain and sustain employment, to form and maintain relationships causing increased levels of anxiety and depression. ${ }^{16}$ They under achieve in school, have increased somatic symptoms and other health problems, have higher than expected rates of unemployment and have reduced rates of marriage in both developed and developing countries. ${ }^{3,7,22,23}$

Epilepsy is considered contagious in many parts of Africa and Asia. ${ }^{24,} 25$ PWE may not be attended to during or after seizures, when simple forms of care could prevent dangerous situation. They are kept away from many family and social activities and functions. Further epilepsy is still classified as a mental illness in the health care structure of many countries. This leads to further discriminative attitudes against PWEs. Although causes of ES are complex, lack of knowledge about epilepsy has been considered to be an important determinant factor. ${ }^{26}$ In the developed world, public attitudes towards epilepsy have greatly improved over the years resulting in more favourable social environment, but negative attitudes still exist in developing countries. ${ }^{27-29}$ There is limited research on ES and associated factors among PWEs in developing countries. Previous Malaysian studies among the general public have shown that the respondents were familiar with epilepsy but many had negative attitudes towards it. ${ }^{30-33}$ The self-perception of those suffering from epilepsy is as important as public attitudes towards it. We therefore conducted this study among PWEs in order to estimate the magnitude of ES and to identify socio-demographic and other determinants so that effective supportive measures could be formulated.

\section{MATERIALS AND METHODS}

This cross-sectional descriptive and analytical study was carried out among 132 PWEs attending the Neurology outpatient clinic at Hospital Tengku Ampuan Afzan (HTAA) Kuantan, a tertiary-care referral centre affiliated to the faculty of Medicine, International Islamic University Malaysia (IIUM) from Dec 2014 to March 2015. The study protocol was approved by the ethical committees of both the HTAA and the faculty of Medicine, IIUM as well as National institutes of health.

PWE of all ages (14 and above on treatment for $>2$ years) were included whereas PWEs with secondary causes of epilepsy like stroke, brain tumour, and any co-morbid systemic or psychiatric illnesses were excluded. PWE who gave their consent were interviewed in the local language (Malay) or English, which ever they were proficient by using a pre-tested, semi-structured questionnaire. The questionnaire focused on collecting information regarding socio-demographic characteristics, seizure characteristics, number of years with epilepsy, knowledge regarding causes of epilepsy, current medical treatments, alternative forms of treatment taken, and perceived stigma. The responses were recorded as 'yes', 'no' and 'Neutral/not sure' where appropriate. In those patients who were not able to provide complete details, parents/ caregivers were also interviewed.

Statistical analyses were carried out using Statistical Package for Social Sciences (SPSS) for Windows version 22.0. Mean and standard deviation for each of the demographic, epilepsy data, and KAPs were recorded. Statistical significance was evaluated using Chi-square test. Kruskal-Wallis test was used to compare the median of two groups. The $p$-value $\leq 0.05$ was considered significant.

For the purpose of group comparisons, the patients 
were grouped into those with; Good KAP and those with Poor KAP. Patients who generated total KAP Score of higher than the group's median were considered to possess good KAP score while those with total KAP score equal to or lower than the group's median were considered as having poor KAP score. The total KAP score is a composite index of 10 questions from the KAP questionnaire below. Each positive response is given 1 mark and negative response is given 0 marks. Maximum applicable mark is 10 and minimum applicable mark is 0 .

\begin{tabular}{ll} 
C1 & Do you know cause of your disease (Epilepsy)? \\
C2 & $\begin{array}{l}\text { Do you think faith healers can treat epilepsy? } \\
\text { D2 }\end{array}$ \\
Do you know that epilepsy is treatable with \\
modern drugs? (Knowledge Q) \\
Do you agree that epilepsy is treatable with \\
modern drugs? (Attitude Q) \\
D4 & $\begin{array}{l}\text { Are you being treated by a Medical Doctor? } \\
\text { (Practice Q) }\end{array}$ \\
D6 & $\begin{array}{l}\text { Do you know you should take regular } \\
\text { treatment for your disease (Knowledge Q) }\end{array}$ \\
D7 & $\begin{array}{l}\text { Do you accept that you should take treatment } \\
\text { regularly (Attitude Q) } \\
\text { Do you attend regular follow-up at your clinic } \\
\text { (Practice Q) } \\
\text { Do you know that you will be benefited by } \\
\text { taking regular treatment (Knowledge Q) }\end{array}$ \\
D9 & $\begin{array}{l}\text { Did you benefit from the medical treatment? } \\
\text { (Practice Q) }\end{array}$ \\
\hline D10 &
\end{tabular}

\section{RESULTS}

The demographic details of patients are shown in Table I. There were 132 patients of whom 68 $(51.5 \%)$ were male and $64(48.5 \%)$ were female and their age ranged from 14 to 70 years (mean $=31.6 \pm$ 13.4). Majority $(53.8 \%)$ of them were aged 30 years or younger. The median number of years they had epilepsy was 8.0 (IQR $4.0-18.8$ ) years and average duration of epilepsy prior to seeking medical attention was 1.0 (IQR $0.3-4.5$ ) years. The average number of years they were receiving treatment from a hospital was $5.5 \pm 5.8$. Most of our respondents were literate $61.4 \%$ had secondary education, $15.2 \%$ had tertiary level education and only $8.3 \%$ respondents were illiterate. Majority of them, $71.2 \%$ belonged to the middle-income group.

Most respondents $(90.9 \%)$ did not know the cause of epilepsy (Table II); however 91.7\% thought that it was a disease of the brain. None of our respondents believed that epilepsy was a mental illness or insanity; however $17.4 \%$ believed that it was contagious. Interrelation between sociodemographic variables and KAP revealed that those between the ages of 21-40 years and 41-60 years seemed to have good KAP compared to extreme ages in the cohort ( $<20$ and $>60$ years), however the

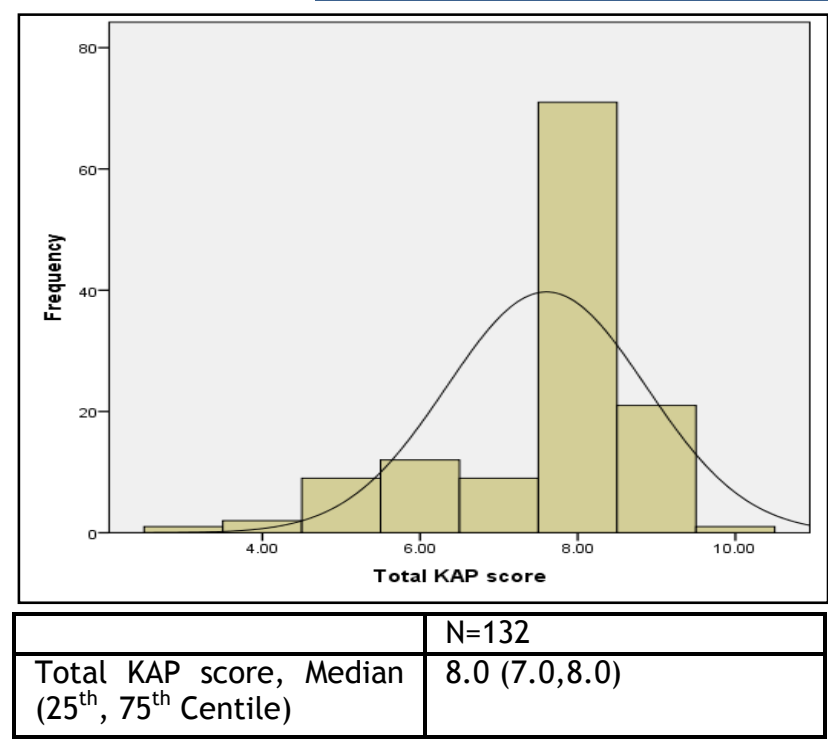

Figure 1. The median score for total KAP is $8.0(7.0,8.0)$. Respondents who scored above the median were considered as having good KAP and those below the median were considered as having poor KAP.

difference was not statistically significant $(p=$ 0.087). There was no significant difference in KAPs between male and female respondents, however higher education level respondents possessed significantly higher KAP scores compared to

Table I. Demographic details of epilepsy patients $(n=132)$

\begin{tabular}{|c|c|c|}
\hline & & Number (\%) \\
\hline $\begin{array}{l}\text { Age (completed } \\
\text { year) Median }\left(25^{\text {th }} \text {, }\right. \\
75^{\text {th }} \text { centiles }\end{array}$ & & $\begin{array}{l}28.5 \\
(21.0,37.8)\end{array}$ \\
\hline Gender & $\begin{array}{l}\text { Male } \\
\text { Female }\end{array}$ & $\begin{array}{l}68(51.5) \\
64(48.5)\end{array}$ \\
\hline Race & $\begin{array}{l}\text { 1. Malay } \\
\text { 2. Chinese } \\
\text { 3. Indian } \\
\text { 4. Others }\end{array}$ & $\begin{array}{l}98(74.20) \\
27(20.5) \\
7(5.3) \\
0(0.0)\end{array}$ \\
\hline Religion & $\begin{array}{l}\text { 1. Islam } \\
\text { 2. Buddhism } \\
\text { 3. Christianity } \\
\text { 4. Hinduism } \\
\text { 5. Others }\end{array}$ & $\begin{array}{l}99(75.0) \\
11(8.3) \\
4(3.0) \\
4(3.0) \\
14(16.0)\end{array}$ \\
\hline Marital status & $\begin{array}{l}\text { 1. Single } \\
\text { 2. Married } \\
\text { 3. Divorced } \\
\text { 4. widowed }\end{array}$ & $\begin{array}{l}82(62.1) \\
49(37.1) \\
- \\
1(0.8)\end{array}$ \\
\hline Education level & $\begin{array}{l}\text { 1.No formal } \\
\text { education } \\
\text { 2. Primary } \\
\text { 3. Secondary } \\
\text { 4. Tertiary level } \\
\text { (College or } \\
\text { University) }\end{array}$ & $\begin{array}{l}11(8.3) \\
20(15.2) \\
81(61.4) \\
20(15.2)\end{array}$ \\
\hline $\begin{array}{l}\text { Occupation } \\
\text { of patient }\end{array}$ & $\begin{array}{l}\text { 1. Unemployed } \\
\text { 2. Employed } \\
\text { 3. Student } \\
\text { 4. House wife } \\
\text { 5. Dependent } \\
\text { 6. Others }\end{array}$ & $\begin{array}{l}43(32.6) \\
60(45.5) \\
23(17.4) \\
6(4.5)\end{array}$ \\
\hline $\begin{array}{l}\text { Estimated average } \\
\text { monthly total } \\
\text { family income }\end{array}$ & $\begin{array}{l}<1,000^{*} \\
1,000-5,000^{*} \\
5,001-10,000^{*} \\
>10,000^{*}\end{array}$ & $\begin{array}{l}31(23.5) \\
94(71.2) \\
6(4.5) \\
1(0.8)\end{array}$ \\
\hline
\end{tabular}

(Ringgit Malaysia*) 
lower education level respondents ( $p<0.001)$. Occupation and household income was not statistically significant. A binary logistic regression, using 'enter' method, was done to determine whether race and education predicted good total KAP score. Both variables (race and education) only predicted $30.1 \%$ of good total KAP score (Nagelkerke $\left.r^{2}=0.31\right)$, and neither achieved statistical significance.

Social impact of epilepsy is shown in Table III. Discrimination by relatives, community, workmates and others was reported by $2.3 \%, 5.5 \%, 0.8 \%$ and $12.9 \%$ respectively while majority of them $72.0 \%$ were not sure whether they were stigmatised or not. Univariate analyses of questions regarding discriminatory attitude/stigma in association with total KAP score are shown in Table IV. We found that good KAP score was associated with significantly better attitudes compared to those with poor KAP score. Respondents with good KAP scores responded that epilepsy was not contagious and had greater social tolerance. Their positive attitude included that PWEs can take a job $(<0.001)$, not object to children playing with children with epilepsy $(<0.001)$, marry $(<0.001)$ and having children $(<0.001)$.

Table II. Knowledge of patients on causes of epilepsy and its treatment

\begin{tabular}{|c|c|c|}
\hline Questions & & Number (\%) \\
\hline $\begin{array}{l}\text { C1. Do you know } \\
\text { the cause of your } \\
\text { disease (epilepsy)? }\end{array}$ & $\begin{array}{l}\text { 1. No } \\
\text { 2. Yes }\end{array}$ & $\begin{array}{l}120(90.9) \\
12(9.1)\end{array}$ \\
\hline C1. If yes, is it & $\begin{array}{l}\text { Disease of } \\
\text { the brain } \\
\text { Due to } \\
\text { supernatural } \\
\text { powers/evil spirits } \\
\text { Familial } \\
\text { Mental disorder/ } \\
\text { insanity } \\
\text { Ignorant } \\
\text { Others }\end{array}$ & $\begin{array}{l}121(91.7) \\
2(1.5) \\
2(1.5)\end{array}$ \\
\hline $\begin{array}{l}\text { C2. Can faith heal- } \\
\text { ers treat epilepsy }\end{array}$ & $\begin{array}{l}\text { 1. No } \\
\text { 2. Yes }\end{array}$ & $\begin{array}{l}98(74.2) \\
30(22.7)\end{array}$ \\
\hline $\begin{array}{l}\text { C3. Have you tried } \\
\text { any other form of } \\
\text { treatment }\end{array}$ & $\begin{array}{l}\text { 1. No } \\
\text { 2. Yes }\end{array}$ & $\begin{array}{l}34(25.8) \\
98(74.2)\end{array}$ \\
\hline C3. If yes, & $\begin{array}{l}\text { 1. Spiritual } \\
\text { 2. Indigenous } \\
\text { 3. Chinese } \\
\text { medicine } \\
\text { 4. Naturopathy } \\
\text { 5. Ayurvedic } \\
\text { 6. Others }\end{array}$ & $\begin{array}{l}2(1.5) \\
14(10.5)\end{array}$ \\
\hline
\end{tabular}

\section{DISCUSSION}

The present study was aimed to obtain information on KAPs of PWE in East Coast of Malaysia and compare the data with previous published Malaysian studies. KAP is a representative study of a specific population to collect information on what the respondents know about their disorder $(\mathrm{K})$, how they feel about it (A), and what they do about it (P), which can be highly relevant in their eventual treatment/ management strategies. ${ }^{34,35}$

Table III. Social impact of epilepsy

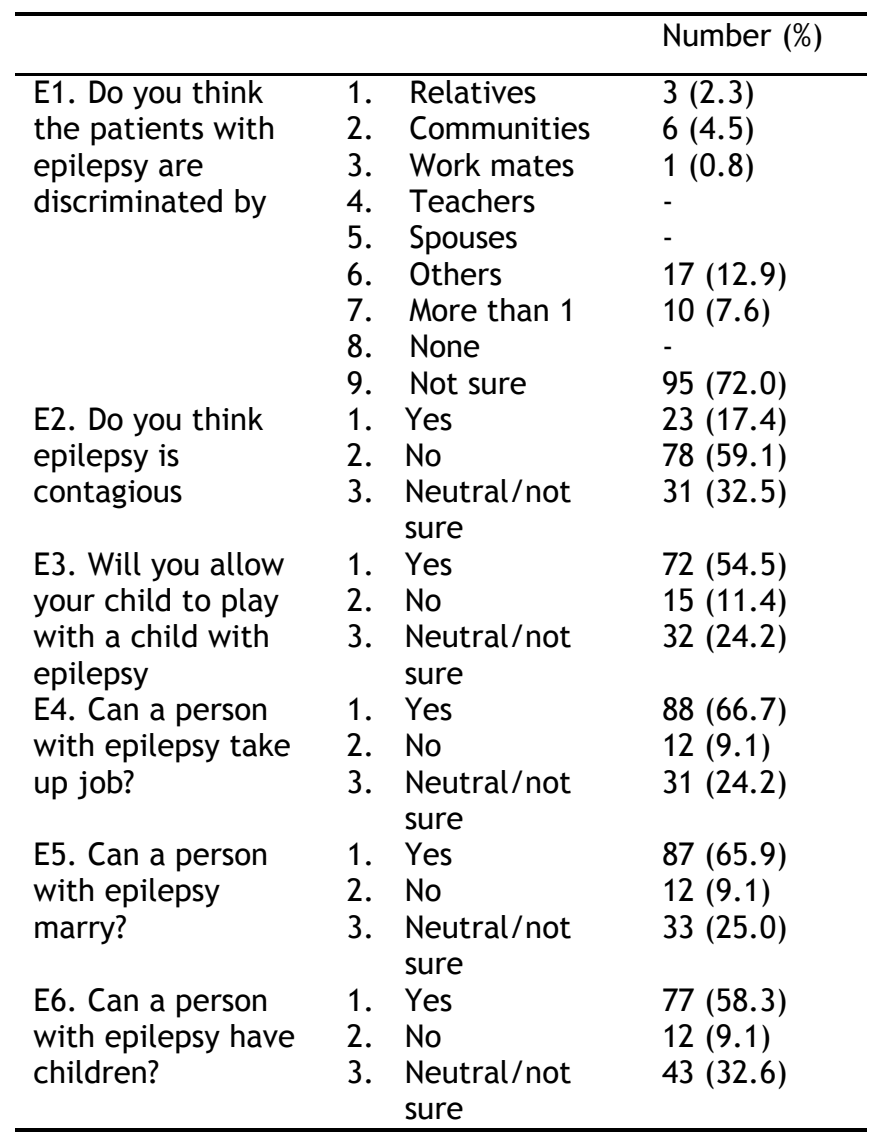

PWEs have substantial psychosocial problems in their everyday life not only due to lack of information, misconception and unfounded fears but also by the social stereotypes concerning it. Our patients had chronic epilepsy and majority of them were young adults. Most of them $(90.9 \%)$ did not know the cause of epilepsy however most $(91.7 \%)$ believed that it was a disease of the brain. Irrespective of demographic parameters such as age, education and duration of the illness, they lacked accurate knowledge about their disorder; a finding similar to other Asian studies. ${ }^{36-41}$ Previous surveys conducted among predominantly Malay population of Kelantan, Malaysia (2000) found that respondents were familiar with epilepsy but had poor knowledge on its cause and treatment and many had a negative attitude towards PWEs. ${ }^{31}$ Another survey (2002) carried out among university students in University Sains Malaysia indicated favourable level of awareness and knowledge of epilepsy but a majority (70\%) of students did not know the cause of epilepsy, $67 \%$ believed that it was acquired through inheritance and $5 \%$ thought that it was caused by evil spirits. ${ }^{32}$ Similarly, another study (2009) was carried out among rural inhabitants of east coast of peninsular Malaysia, which revealed disproportionately poor awareness and knowledge about epilepsy along with indifferent attitudes. ${ }^{33}$ Yet 
Table IV. Univariate analyses of questions regarding discriminatory attitude/stigma in association with total KAP score.

\begin{tabular}{|c|c|c|c|c|}
\hline & \multicolumn{2}{|c|}{$\begin{array}{l}\text { Total KAP score, } \\
\mathrm{N}(\%)\end{array}$} & \multirow[t]{2}{*}{ p-value } \\
\hline & & Poor & Good & \\
\hline \multirow{3}{*}{$\begin{array}{l}\text { Epilepsy } \\
\text { is } \\
\text { conta- } \\
\text { gious }\end{array}$} & Yes & $3(9.1)$ & $18(19.4)$ & $<0.001$ \\
\hline & No & $10(30.3)$ & $64(86.8)$ & \\
\hline & Not Sure & $20(60.6)$ & $11(11.8)$ & \\
\hline \multirow{3}{*}{$\begin{array}{l}\text { Allow } \\
\text { children } \\
\text { to play } \\
\text { with a } \\
\text { child } \\
\text { with } \\
\text { epilepsy }\end{array}$} & Yes & $5(15.2)$ & $61(65.6)$ & $<0.001$ \\
\hline & No & $4(12.1)$ & $11(11.8)$ & \\
\hline & Not Sure & $24(72.7)$ & $21(22.6)$ & \\
\hline \multirow{3}{*}{$\begin{array}{l}\text { Person } \\
\text { with } \\
\text { epilepsy } \\
\text { can take } \\
\text { up a job }\end{array}$} & Yes & $10(30.3)$ & $72(77.4)$ & $<0.001$ \\
\hline & No & $7(21.2)$ & $5(5.4)$ & \\
\hline & Not Sure & $16(48.5)$ & $16(17.2)$ & \\
\hline \multirow{3}{*}{$\begin{array}{l}\text { Person } \\
\text { with } \\
\text { epilepsy } \\
\text { can } \\
\text { marry }\end{array}$} & Yes & $11(33.3)$ & $71(76.3)$ & $<0.001$ \\
\hline & No & $4(12.1)$ & $8(66.7)$ & \\
\hline & Not Sure & $18(54.5)$ & $14(15.1)$ & \\
\hline \multirow{3}{*}{$\begin{array}{l}\text { Person } \\
\text { with } \\
\text { epilepsy } \\
\text { can have } \\
\text { children }\end{array}$} & Yes & $7(21.2)$ & 65 (69.9) & $<0.001$ \\
\hline & No & $5(15.2)$ & $7(7.5)$ & \\
\hline & Not Sure & $21(63.6)$ & $21(22.6)$ & \\
\hline
\end{tabular}

another study (2010) was conducted among Chinese population in the selected areas of peninsular Malaysia which revealed good knowledge and positive attitudes toward certain aspects of epilepsy but a minority of the study participants demonstrated prejudice and discriminatory behaviour towards PWEs. ${ }^{30}$ Analysis of Malaysian studies revealed regional differences in KAPs which could be attributed to local factors, such as literacy, awareness about epilepsy, and category of study population.

Although epilepsy is often perceived as a supernatural ailment, caused by ancestral spirits or attributed to possession by evil spirits, only a few of our respondents $(1.5 \%)$ believed in evil spirits as a cause and understandably they did not perceive any benefit from traditional healers which are aimed at driving out evil spirits. Low levels of literacy and limited medical information contribute to the persistence of these negative cultural beliefs.

In many parts of Africa and Asia, epilepsy is considered to be contagious. ${ }^{24,25}$ Among our respondents $17.4 \%$ believed that epilepsy was contagious. However, respondents with good KAP score believed that epilepsy was not contagious and had greater social tolerance. Their positive attitude included that PWEs can take a job $(<0.001)$, not object to children playing with children with epilepsy $(<0.001)$, marry $(<0.001)$ and having their children $(<0.001)$. In Nigeria, epilepsy is commonly thought to be contagious, even among medical students; hence PWEs are avoided. ${ }^{42} \mathrm{~A}$ study among Tanzanian individuals revealed that $40.6 \%$ of them believed that epilepsy was infectious and could be spread through physical contact. ${ }^{43}$ Consequently, PWE may not be attended to during or after seizures, because people are afraid of being contaminated by their sweat, urine, saliva, flatus, and even breath.

Despite the fact that epilepsy is still classified as a mental illnesses in the health care structure of many countries, none of our respondents believed that it was a mental illness or insanity, which was positive compared to earlier studies done in Malaysia, Vietnam and in South India where 23\%, 20.5\% and $27.3 \%$, respectively thought epilepsy as type of mental illness. ${ }^{31,39,44}$ The possible reason behind this better understanding could be the education level of our respondents, $61.4 \%$ of whom had secondary education and $15.2 \%$ had tertiary level education. Higher education level respondents possessed significantly higher KAPs score compared to lower education level respondents $(p<0.001)$. However, occupation and household income was not statistically significant. There was no significant difference in KAPs based on gender among our respondents which probably is due to the fact that both males and females have equal opportunities in the fields of education, occupation etc in Malaysia. It could also mean that both males and females received equal exposure with regard to this disease. This particular finding was supported by Lim et al, who claimed that gender did not have a significant association with the awareness of epilepsy.

In terms of age group, those between the age of 21 40 years and 41-60 years seems to have good KAP compared to extreme ages in the cohort $(<20$ and $>60$ years), however the difference was not statistically significant $(p=0.087)$. Among our respondents discrimination by relatives, community, workmates and others was reported by $2.3 \%, 5.5 \%$, $0.8 \%$ and $12.9 \%$ respectively while a majority of them $(72.0 \%)$ were not sure whether they were stigmatised. From this we speculated that they had self-perceived stigma, which was quite high, a finding similar to other studies. High rate of stigmatisation was also reported by a European study where more than half of all epileptic patients $(51 \%)$ experienced this sometime in their lives. ${ }^{24}$ Another large study among PWEs from Iran, the Gulf, and Near East regions revealed that more than one third of all respondents in the study felt stigmatized by their epilepsy, and $11 \%$ felt highly stigmatized by their condition. ${ }^{25}$ However some studies have reported low levels of stigmatisation in their community. As we predicted, self-perceived stigma 
was perceived by most of our patients, that is an indication of the gravity of the situation and the main reason was lack of accurate knowledge regarding their illness.

We believe that the negative social attitudes observed in certain segments of the community need to be challenged by educational campaigns through community settings and social segments. This will improve the general public's understanding about epilepsy and thus improve society's acceptance of PWE. Further information campaigns designed to improve the students' knowledge of epilepsy should be encouraged at schools, educational institutions and universities so that future generations no longer consider epilepsy as a stigma. Finally we must improve the knowledge of PWE so that they get the right perspective of their illness.

\section{Limitations of the study}

There are some limitations to this study that need to be mentioned. The patients were approached from the neurology clinic of a tertiary Hospital where they followed-up; hence the results may not be reflective of the whole of Malaysia. Secondly, there is potential for information bias; PWE may have attempted to answer the questions in ways they perceived as socially desirable, rather than revealing the whole truth. The questionnaire was specifically designed to elicit information on KAPs among PWEs towards their condition rather than gauge psychosocial functioning or quality of life. Furthermore, the use of structured questions does not allow detailed exploration of the reasons that the perceivers of stigma hold about a condition such as the one under investigation here. This could form the basis of further study.

\section{CONCLUSION}

The present study suggests that PWEs in Malaysia have limited knowledge about their disorder regardless of age, educational background, or number of years with epilepsy and self-perceived stigma was the most common stigma subtype among them. The results suggest that there is a critical need to enhance epilepsy education amongst them as well as among general public so that they get the right perspective of this disease.

\section{REFERENCES}

1. Fisher RS, van Emde BW, Blume W, Elger C, Genton $\mathrm{P}$, Lee $\mathrm{P}$, et al. Epileptic seizures and epilepsy: definitions proposed by the International League against Epilepsy (ILAE) and the International Bureau for Epilepsy (IBE). Epilepsia. 2005; 46:470-2.

2. Kobau R, Price P. Knowledge of epilepsy and familiarity with this disorder in the U.S population: Results from the 2002 health styles survey. Epilepsia. 2003; 44: 1449-54.
3. De Boer HM, Mula M, Sander JW. The Global Burden and Stigma of Epilepsy. Epilepsy Behav. 2008; 12: 540-6.

4. Kwan P, Brodie MJ. Early identification of refractory epilepsy. N Engl J Med. 2000; 342:314-9.

5. Lim, Y.J., S.Y. Chan and Y. Ko. Stigma and health-related quality of life in Asian adults with epilepsy. Epilepsy Res. 2009; 87: 107-119.

6. Rafael, F., D. Houinato, P. Nubukpo, C.M. Dubreuil and D.S. Tran et al. Socio-cultural and psychological features of perceived stigma reported by people with epilepsy in Benin. Epilepsia. 2010; 6: 1061-68

7. McCagh J., Fisk J.E., Baker G.A. Epilepsy, psychosocial and cognitive functioning. Epilepsy Research. 2009; 86: 1-14.

8. De Boer HM. Epilepsy stigma: Moving from a global problem to global solutions. Seizure. 2010; 19:630-36.

9. McCagh J. Epilepsy, myths, stereotypes \& stigma. Brain Research Journal 2010; 375- 88.

10. Dilorio C, Shafer OP, Letz R, Henry T, Schomer $\mathrm{DL}$, Yeager $\mathrm{K}$. The association of stigma with self-management and perceptions of health care among adults with epilepsy. Epilepsy Behav. 2003; 4:259-67.

11. Hosseini N, Sharif F, Ahmadi F, Zareh M. Struggle with stigma of Iranians with epilepsy. Epilepsy Behav.2010; 17:600.

12. Tekle-Haimanot R, Abebe M, Forsgren L, GebreMariam A, Heijbel J, Holmgren G, et al. Attitudes of rural people in central Ethiopia toward epilepsy. Soc Sci Med. 1991; 32:203-9.

13. Atadzhanov M, Haworth A, Chomba EN, Mbewe EK, Birbeck GL. Epilepsy associated stigma in Zambia: What factors predict greater felt stigma in a highly stigmatized population. Epilepsy Behav.2010; 19:414-8.

14. Aydemir N, Trung DV, Snape D, Baker GA, Jacoby A. Multiple impacts of epilepsy and contributing factors findings from an ethnographic study of Vietnam. Epilepsy Behav.

15. 2009; 16:512-20

16. Li S, Wu J, Wang W, Jacoby A, deBoer $\mathrm{H}$, Sander JW. Stigma and epilepsy: The Chinese perspective. Epilepsy Behav. 2010; 17:242-5.

17. Baker GA, Brooks J, Buck D, Jacoby A. The stigma of epilepsy: A European perspective. Epilepsia.1999; 41:98-104.

18. Goffman E: Stigma: Notes on the Management of Spoiled Identity. Upper Saddle River, NJ: Prentice Hall; 1963.

19. KS Lim, CT Tan Epilepsy stigma in Asia: the meaning and impact of stigma. Neurology Asia 2014; 19(1): 1 - 10

20. Dell, J.D. Social dimensions of epilepsy: stigma and response. in: S. Whiteman, B.P. Hermann (Eds.) Psychopathology in epilepsy. Oxford University Press, New York; 1986

21. Karakas I, Cole AJ, Montouris GD, et al. Caregiver burden in epilepsy: Determinants and impact. Epilepsy Research and Treatment 2014: 
Article ID 808421. Available at: http:// dx.doi.org/10.1155/2014/808421

22. Saengsuwan J, Laohasiriwong W, Boonyaleepan S, et al. Knowledge, attitudes, and care techniques of caregivers of PWE in north eastern Thailand. Epilepsy \& Behaviour. 2013; 27: 257-63.

23. Baker GA, Brooks J, Buck D, et al. The stigma of epilepsy: a European perspective. Epilepsia 2000, 41: 98- 104.

24. Baker GA, Jacoby A, Gorry J, Doughty J, Ellina V. Quality of life of people with epilepsy in Iran, the Gulf, and Near East. Epilepsia. 2005; 46:132-40.

25. Birbeck G, Chomba E, Atadzhanov M, Mbewe $E$, Haworth A. The social and economic impact of epilepsy in Zambia: a cross-sectional study. Lancet Neurol. 2007; 6:39-44.

26. Baskind R, Birbeck GL. Epilepsy-associated stigma in Sub-Saharan Africa: The social landscape of a disease. Epilepsy Behav. 2005; 7:68-73.

27. G.A. Baker, A. Jacoby, H. DeBoer, J. Doughty, E. Myon, C. Taieb. Patients understanding of the adjustment to epilepsy: interim findings from European survey Epilepsia. 1999; 40 (9): 26-29.

28. Mirnics Z, Czikora G, Za'vecz T, Hala'sz P. Changes in public attitudes toward epilepsy in Hungary: results of surveys conducted in 1994 and 2000. Epilepsia 2001; 42:86-93.

29. Jacoby A. Stigma, epilepsy, and quality of life. Epilepsy Behav 2002; 3:S10-20.

30. Seneviratne U, Rajapakse P, Pathirana R, Seetha T. Knowledge, attitude, and practice of epilepsy in rural Sri Lanka. Seizure 2002; 11:40-3.

31. Shahzad S Hasan, Wayne WG Wei, Keivan Ahmadi, Imran S Ahmed, Alen KS Yong, Mudassir Anwar. Knowledge and Attitudes toward Epilepsy among Malaysian Chinese. IJCRIMPH. 2010; 2(11): 361-376

32. Ramasundrum V, Zabidi AMH, Chong TT: Public awareness, attitudes and understanding towards epilepsy in Kelantan, Malaysia. Neurol J Southeast Asia 2000; 5:55-60.

33. Rahman AFA: Awareness and knowledge of epilepsy among students in a Malaysian university. Seizure. 2005; 14(8):593-96.

34. Neni SW, Latif AZ, Wong SY, Lua PL. Awareness, knowledge and attitudes towards epilepsy among rural population in East Coast Peninsular Malaysia: A preliminary exploration. Seizure. 2010; 19(5): 280-90.

35. Ellen Vandamme. (2009) Concepts and challenges in the use of Knowledge-AttitudePractice surveys: Literature review

36. Wood, S. \& Tsu, V. (2008) Advocacy, communication and social mobilization for TB control: a guide to developing knowledge, attitude and practice surveys, WHO Library Cataloguing-in-Publication Data. http:// www.stoptb.org/resource_center/assets/
documents/ACSM_KAP\%20GUIDE.pdf

37. Lai CW, Huang X, Lai YHC, Zhang Z, Liu G, Yang MZ. Survey of public awareness, understanding and attitudes towards epilepsy in Henan Province, China. Epilepsia. 1990;31:182-7

38. Chung MY, Chang YC, Lai CW. Survey of public awareness, understanding and attitudes towards epilepsy in Taiwan. Epilepsia. 1995;36:488-93

39. Gambhir SK, Singhi PD, Goel RC. Public awareness, understanding and attitudes toward epilepsy. Indian J Med Res. 1995; 102: 34-8.

40. Radhakrishnan K, Pandian JD, Santhosh K T: Prevalence, Knowledge, Attitude and Practice of Epilepsy in kerala, South India. Epilepsia. 2000; 41(8):1027-35.

41. Lim KS, Tan LP, Lim KT, Tan CT. Survey of public awareness, understanding and attitudes towards epilepsy in Malaysia. Neurol J Southeast Asia. 1999;4:31-36

42. Pan APS, Lim SH. Public awareness, attitudes and understanding toward epilepsy among Singaporean Chinese. Neurol J Southeast Asia. 2000; 5:5-10.

43. Ojinnaka NC. Teachers' perception of epilepsy in Nigeria: a community-based study. Seizure. 2002; 11: 386-91.

44. Jilek WG. The epileptic outcast role and its background: a contribution to the social psychiatry of seizure disorders. J Oper Psychiatry. 1979; 10: 127-33.

45. Tuan NA, Cuong LE, Allebeck P, Chuc NTK,Tomson T. Knowledge, Attitudes and Practice toward Epilepsy among Adults in BaVi, Vietnam. Epilepsia. 2007; 48(10):1914-19. 
